\title{
Corrigendum
}

\section{Corrigendum to "Experimental Study on the Effects of Initial Shear Stress and Vibration Frequency on Dynamic Strength of Saturated Sands"}

\author{
Jian Zhang $\mathbb{D}^{1},{ }^{1}$ Jiuting Cao, ${ }^{2}$ and Sijie Huang ${ }^{3}$ \\ ${ }^{1}$ Nanjing Vocational Institute of Transport Technology, Nanjing 211188, China \\ ${ }^{2}$ Jiangsu Zhongshe Group Co., Ltd., Wuxi 214072, China \\ ${ }^{3}$ Tianjin Institute of Water Transport Engineering, Ministry of Transport, Tianjin 300456, China \\ Correspondence should be addressed to Jian Zhang; 18626439990@163.com
}

Received 16 July 2020; Accepted 17 July 2020; Published 18 September 2020

Copyright (c) 2020 Jian Zhang et al. This is an open access article distributed under the Creative Commons Attribution License, which permits unrestricted use, distribution, and reproduction in any medium, provided the original work is properly cited.

In the article titled "Experimental Study on the Effects of Initial Shear Stress and Vibration Frequency on Dynamic Strength of Saturated Sands" [1], the author Jian Zhang was affiliated to the School of Architectural Engineering, Nanjing Institute of Technology, Nanjing 211167, China, which is incorrect. The corrected list of affiliations is shown above.

\section{References}

[1] J. Zhang, J. Cao, and S. Huang, "Experimental study on the effects of initial shear stress and vibration frequency on dynamic strength of saturated sands," Advances in Materials Science and Engineering, vol. 2019, Article ID 3758527, 9 pages, 2019. 